\title{
Animal models for the study of primary and secondary hypertension in humans (Review)
}

\author{
HIU YU LIN ${ }^{1}$, YEE TING LEE ${ }^{1}$, YIN WAH CHAN ${ }^{2}$ and GARY TSE ${ }^{3}$ \\ ${ }^{1}$ School of Biomedical Sciences, Li Ka Shing Faculty of Medicine, University of Hong Kong, Hong Kong, SAR, P.R. China; \\ ${ }^{2}$ School of Biological Sciences, University of Cambridge, Cambridge CB2 1AG, UK; ${ }^{3}$ Department of \\ Medicine and Therapeutics, Chinese University of Hong Kong, Hong Kong, SAR, P.R. China
}

Received July 25, 2016; Accepted September 2, 2016

DOI: $10.3892 /$ br.2016.784

\begin{abstract}
Hypertension is a significant cause of morbidity and mortality worldwide. It is defined as systolic and diastolic blood pressures (SBP/DBP) >140 and $90 \mathrm{mmHg}$, respectively. Individuals with an SBP between 120 and 139, or DBP between 80 and $89 \mathrm{mmHg}$, are said to exhibit pre-hypertension. Hypertension can have primary or secondary causes. Primary or essential hypertension is a multifactorial disease caused by interacting environmental and polygenic factors. Secondary causes are renovascular hypertension, renal disease, endocrine disorders and other medical conditions. The aim of the present review article was to examine the different animal models that have been generated for studying the molecular and physiological mechanisms underlying hypertension. Their advantages, disadvantages and limitations will be discussed.
\end{abstract}

\section{Contents}

1. Introduction

2. Overview of different animal models

3. Advantages and disadvantages of these model systems

4. Renal models

5. Pharmacological models

6. Environmental models

7. Genetic models

8. Inbreeding

9. Transgenic strains

10. Concluding remarks

Correspondence to: Dr Gary Tse, Department of Medicine and Therapeutics, Chinese University of Hong Kong, 30-32 Ngan Shing Street, Hong Kong, SAR, P.R. China

E-mail: gary.tse@doctors.org.uk

Key words: animal models, mouse, rat, vascular function, endothelium, hypertension

\section{Introduction}

Hypertension is one of the most important risk factors for the development of cardiovascular disease and is responsible for $>50 \%$ of the 17 million deaths per year worldwide (1). It is a heterogeneous condition with a number of etiologies and multiple, interacting genetic and environmental factors (2). Its incidence varies with age, plasma renin activity and sodium sensitivity (3). The use of pre-clinical animal models has significantly increased our understanding of disease processes, as these permit the control of the different contributing factors. However, no single system is ideal, as there are species differences and other limitations of these model systems $(4,5)$. Species, including mice, have been popular for the study of cardiometabolic disorders due to their amenability to genetic and pharmacological modification (6-12). It is not the aim of the present review to provide an exhaustive list of the different models, but to discuss historically important model systems whose use has significantly advanced our understanding of hypertension.

\section{Overview of different animal models}

Animal models of hypertension can be categorised according to aetiology (13) (Fig. 1). Renal diseases, including renal arterial stenosis (RAS), are major causes of secondary hypertension. RAS has been modelled by the 2 kidneys-1 clip hypertension model (2K-1C), 1 kidney-1 clip hypertension model (1K-1C) and 2 kidney-2 clip hypertension model $(2 \mathrm{~K}-2 \mathrm{C})$. Other systems have been devised to examine the pathophysiology of renal parenchymal hypertension, renal ischemia and perinephric fibrosis. A deoxycorticosterone acetate (DOCA)-induced model imitates the effects of mineralocorticoid- and glucocorticoid-induced hypertension. Pharmacological approaches using a nitric oxide synthase (NOS) inhibitor or by activating the renin-angiotensin-aldosterone-system (RAAS), or introduction of environmental stresses, including stress, cold temperature and diet, have also been performed to induce hypertension. Essential hypertension has been investigated using spontaneously hypertensive rats (SHRs), Dahl salt-sensitive and other rat strains (14). Other molecular models, transgenic strains, consomic and 
congenic strains, combined with gene knockout techniques have been used to examine the mechanistic basis of essential hypertension.

\section{Advantages and disadvantages of these model systems}

Initial experiments for the investigation of hypertension were performed in dogs. Such experiments included the renovascular models developed by Goldblatt et al (15) in 1934. Subsequent models using rats, rabbits, sheep and cats were developed (16). Pigs have also been used, in particular, the Yucatan model for the study of DOCA-induced hypertension (17).

Of the different species, rat has been a popular model as a result of the availability of different inbred strains and characteristics, including the SHR, Dahl salt-sensitive rats, New Zealand and Milan strains (18). Numerous justifications for using rats to model hypertension exist. Firstly, its genome has been completely mapped, with a $99 \%$ sequence homology to humans (19). Secondly, the pathogenesis of hypertension in rats and humans are largely similar in terms of arterial pressure development from childbirth, response to environmental stressors, haemodynamic factors (including vascular resistance), mechanisms regulating arteriolar and venous constriction, neural modulation (including sympathetic nerve activity) and renal vascular dynamics (including perfusion parameters), as well as humoral influences by RAAS and NOS (20). The advantages are that they are low cost, with wide availability and easy to handle, maintain and breed. However, these models also have their limitations. Firstly, the identical genotype may not induce the same phenotype in all animals (21) due to contributions from numerous genes and the additional environmental influences $(22,23)$. Secondly, the same gene mutations and deletion observed in rats may not induce to the identical phenotypic effects in humans (24).

Larger animals have closer anatomical, physiological and haemodynamic properties to humans when compared with small animals, including rats and mice, making them particularly suitable for the study of flow characteristics $(25,26)$. However, the major disadvantage is the high costs required for their maintenance. Additionally, the domestication of dogs has led to their decreasing use for research (27).

\section{Renal models}

Renovascular hypertension. The kidney-clip models mimicking renal arterial stenosis were first performed in dogs (15), which have been gradually replaced by smaller animals. In the $2 \mathrm{~K}-1 \mathrm{C}$ model, one of the two renal arteries is constricted by a clip (28). Initially, decreased renal arterial pressure in the clipped kidney leads to increased plasma renin activity (PRA) with higher circulating levels of renin and aldosterone (29). This is followed by the return of the PRA to a near normal level, and finally by chronically elevated PRA (30). Patients with renovascular hypertension exhibit similar patterns of PRA (31). The underlying mechanism involves RAAS activation, increased renin production and subsequent angiotensin (Ang)-I release and conversion by Ang converting enzyme (ACE) to Ang-II. The net effects are further vasoconstriction and increased production of aldosterone level, which together lead to water and salt retention, and an increased blood pressure. In addition, the model also reveals increased sympathetic nerve activity that further drives renin production (32). The $2 \mathrm{~K}-2 \mathrm{C}$ model, where both renal arteries are constricted, resemble bilateral renal arterial stenosis in humans and the mechanism involved is similar to the $2 \mathrm{~K}-1 \mathrm{C}$ model, but with a more severe phenotype (33).

In the $1 \mathrm{~K}-1 \mathrm{C}$ model, unilateral nephrectomy is performed with a constricting clip on the renal artery of remaining kidney (34). This resembles patients who suffer from RAS of the solitary kidney (35). Similar to the previous renal models, initial elevation of blood pressure is due to RAAS activation. However, because of the absence of a functional kidney, no compensatory rise in sodium and water excretion is observed. Consequently, more fluid is retained inside the body. In other words, this is more volume- rather than RAAS-dependent. This is consistent with the experimental findings that ACE inhibition was unable to prevent chronic hypertension in renal artery stenosis of a solitary kidney, however, was successful in doing so where a normal functioning kidney is present (36).

Renal parenchymal hypertension. Renal parenchymal hypertension is the commonest cause of secondary hypertension and is responsible for up to 5\% of all cases (37). Subtotal nephrectomy ablation, in which up to $5 / 6$ of the kidney is removed, has been performed to induce chronic renal disease (38). This model demonstrates glomerular, tubular and interstitial injury, loss of nephrons and the development of hypertension. It can be combined with the introduction of excess salt into the diet to increase the severity and speed of onset of this hypertension. The mechanism is dependent on the RAAS and the hypertension can be reduced by ACE inhibition. Renal ischemia has been produced by microembolisation, which led to the development of nephrosclerosis and hypertension (39). Perinephric fibrosis has been induced by wrapping the kidney in cellophane, mimicking fibrosis that occurs after kidney transplantation (40).

\section{Pharmacological models}

Mineralocorticoids or their synthetic derivatives, including DOCA, are used with sodium chloride in unilateral nephrectomised rats to induce hypertension $(41,42)$. Renin is suppressed and fluid reabsorption is increased, thereby producing a low renin-volume overload model of hypertension (43). Using this model, key sodium-independent mechanisms for mediating hypertension, including upregulation of Ang-II receptors in the central nervous system (44), elevated vasopressin (45), increased oxidative stress (46) and endothelin (47), have been identified. Aside from elucidating the molecular mechanisms underlying renal hypertension, it provides a useful platform for investigating the natural history of disease, including any complications, such as glomerulosclerosis, proteinuria, impaired endothelium-dependent relaxation of the vasculature and cardiac hypertrophy can be investigated (42). In the DOCA-hypertensive Yucatan miniature swine model, excess dietary salt is not required for sustaining hypertension due to enhanced SNS activity at baseline, as evidenced by the increased plasma norepinephrine level (48). Glucocorticoids can also be used to induce hypertension (49). Although hypertension is produced via RAAS activation, this approach is 


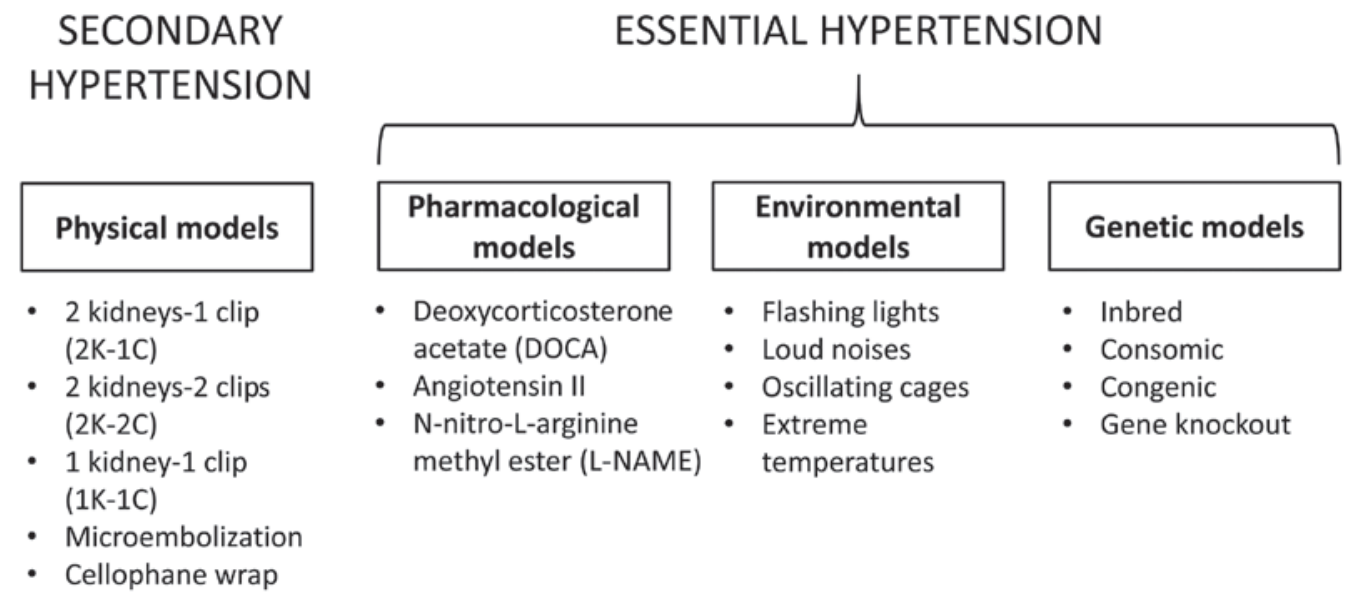

Figure 1. Different types of animal models for primary and secondary hypertension.

less effective than the DOCA-salt method. An alternative is chronic infusion of RAAS components, including Ang-II (50).

Nitric oxide (NO), a potent vasodilator derived from the intact endothelium, is produced by NOS. This production is triggered by vasoactive messengers, including acetylcholine (51). A NO-deficient model was produced by chronic infusion of N-nitro-L-arginine methyl ester (L-NAME), a NOS inhibitor (52). A low dose produced a volume-dependent increase in blood pressure predominantly due to renal vasoconstriction and decreased glomerular filtration (53). A high dose led to both salt- and volume-independent hypertension since the mechanism is renal and systemic vasoconstriction (54).

\section{Environmental models}

Environmental stress, including separate or simultaneous introduction of flashing lights, loud noises and oscillating cages (55-57), or long-term exposure to high salt, fat or sugar in the diet, can be used to induce hypertension (58). Extremes of temperature, particularly coldness, also induces a hypertensive phenotype, as observed in rats exposed to $5^{\circ} \mathrm{C}$ for 3 weeks (59). In these animals, increases in plasma and urine catecholamines were observed (60). These findings are consistent with findings in humans, where those who work chronically in cold areas develop hypertension (61) and higher values of blood pressure recorded in winter compared with in the summer (62). Increased activity of the sympathetic nervous system and RAAS activation appear to be the common physiological mechanisms responsible for hypertension in the models described above $(60,63,64)$.

\section{Genetic models}

Genetic factors are estimated to influence up to $50 \%$ of blood pressure variability in essential hypertension (65). The millennium genome project for hypertension was initiated in 2000 to identify genetic variants that predispose individuals to hypertension. This has involved a combination of techniques, including a gene linkage approach using single nucleotide polymorphisms, microsatellite markers and systematic candidate gene analysis (66). In parallel with this has been the development of genetic models using different animal species, which have provided insights into the physiological mechanisms of hypertension. These can be categorised into inbreeding, consomic, congenic and subcongenic strains (18), which will be considered in turn.

\section{Inbreeding}

The inbreeding method involves sibling mating of hypertensive rats over several generations to produce strains with genetic homogeneity when compared with the reference control group.

Spontaneous hypertension models. SHR and stroke-prone SHR strains closely simulate essential hypertension $(20,67)$. Both development impaired endothelium-dependent relaxation, cardiac hypertrophy and failure, as well as renal dysfunction, are involved (68). These represent normal renin, sodium-independent models of hypertension (69). SHRs were produced by breeding brother Wistar rats with their sisters and selecting the offspring with the highest blood pressures (70). In SHRs, increases in systolic blood pressures to $180-200 \mathrm{mmHg}$ after 4 weeks of growth were observed, compared with the Wistar-Kyoto rats (WKY) that remain normotensive. It is worthwhile to note that WKY strains are not inbred, and therefore there is substantial genetic heterogeneity between these strains and between colonies within each strain (71). Consequently, no specific genetic components are associated with hypertension in the control WKY group.

SHRs have been used to determine the genes responsible for hypertension, to evaluate complications of target organs and the screening potential pharmacological agents for treatment. In stroke-prone SHRs, it was shown that dietary potassium supplementation decreases the risk of cerebrovascular accidents, even when blood pressure was not lowered (72). At least three genetic loci have been implicated in the early development of hypertension, with an additional gene identified on chromosome 10 contributing to its maintenance with aging (73). The New Zealand hypertensive rats are similar to Japanese SHRs in developing spontaneous hypertension (74), as do the Milan $(20)$ and Lyon $(75,76)$ strains.

Salt-sensitive hypertension models. Dahl salt-sensitive (DS) rat strains are prone to hypertension following administration 
of a low-salt diet $(0.4 \% \mathrm{NaCl})$, unlike Dahl salt-resistant (DR) rat strains, which remain normotensive (77). DS strain rats fed with a high-salt diet $(8 \% \mathrm{NaCl})$ develop particularly severe hypertension (78). The reason is that the certain alleles at the genetic loci for ACE and guanylyl cyclase A, causing DS rats to have increased $\mathrm{ACE}$ and decreased atrial natriuretic factor (ANF, the ligand for guanylyl cyclase A) (79). The Sabra strain also demonstrates salt-sensitive hypertension (80).

Other inbred models. The Fawn hooded hypertensive rats develop hypertension due to glomerular sclerosis, and therefore serve as a model for renal parenchymal disease (81). Sprague-Dawley rats, obese Zucker, Wistar fatty rats have been used to assess the effects of diet-induced obesity on the development of hypertension (82).

\section{Transgenic strains}

Transgenic technology can be used to investigate the specific role of different genes in the regulation of blood pressure (83). Broadly, the approaches are generation of consomic and congenic strains, and gene knockout.

Congenic and consomic strains. A congenic strain refers to one in which a defined chromosome segment is introduced to another by backcrossing with appropriate selection (84). In the case of a consomic strain, the entire chromosome is transferred (85). For example, the mutant renin gene from mouse was transferred to rats, producing elevated Ang-II levels and hypertension (86), which were prevented by ACE inhibition (87). Similarly, insertion of the human renin gene into mice also consistently demonstrated activation of genes involved in the RAAS $(88,89)$.

Gene knockout. Gene targeting permits targeted disruption, including deletion, overexpression or subtle mutations, of a gene product. Conditional knockout with tissue- and time-dependent specificity is also possible, allowing investigation of the loss of a particular gene at specific time points or in particular organs. Gene knockout is often performed in mice because of the relative ease in introducing genetic mutations, and this has led to an increased understanding of different cardiovascular disorders with potential for translational application (90-99). Knockout of the angiotensinogen gene provided protection in delaying the development of hypertension and increasing NO availability compared with wild-type, thereby implicating the RAAS as being critical in blood pressure regulation (100). However, each group demonstrated similar extents of cardiac hypertrophy, suggesting RAAS-independent mechanisms for this response. Knockout of genes encoding for endothelial NOS (101) and atrial natriuretic peptide develop hypertension, whereas Ang-II type 1a receptor knockout rats demonstrate hypotension (102). The importance of the aldosterone pathway was shown in a mineralocorticoid receptor mutation conferring constitutive receptor activity led to early onset hypertension (103). Liddle syndrome, an autosomal dominant cause of pseudoaldosteronism, leading to human hypertension, was shown to involve a mutated epithelial sodium channel (104).

Certain limitations of genetic knockout models require addressing. Firstly, the expression of certain gene deletions may result in embryonic lethality so there is lack of time to study the pathogenesis; secondly, redundancy among isoforms causes phenotypic expression to be masked so sometimes double or triple gene knockout is required. It is also important to note that same gene deletion or overexpression in animals may lead to different expression in phenotypes (24).

\section{Concluding remarks}

Different pharmacological, environmental and genetic models using different animal species have provided useful and valuable information on the aetiology, pathophysiology and complications of human cardiovascular and metabolic disorders, and a platform to examine the efficacy of pharmacotherapy (105-118). However, a major limitation of these experimental models is the anatomical differences between these animal species and humans (119). Although the common mechanism is RAAS activation across different species, species differences must be carefully taken into consideration to ensure the safety of newly developed pharmacological agents.

\section{Acknowledgements}

The present review was funded by a Biotechnology and Biological Sciences Research Council Doctoral Training Award at the University of Cambridge awarded to Dr Gary Tse and the Economic and Social Research Council grant awarded to Miss Yin Wah Fiona Chan at the University of Cambridge.

\section{References}

1. Chen R, Dharmarajan K, Kulkarni VT, Punnanithinont N, Gupta A, Bikdeli B, Mody PS and Ranasinghe I: Most important outcomes research papers on hypertension. Circ Cardiovasc Qual Outcomes 6: e26-e35, 2013.

2. Galosy RA, Clarke LK, Vasko MR and Crawford IL: Neurophysiology and neuropharmacology of cardiovascular regulation and stress. Neurosci Biobehav Rev 5: 137-175, 1981.

3. Weinberger MH: Salt sensitivity of blood pressure in humans. Hypertension 27: 481-490, 1996.

4. Sarikonda KV, Watson RE, Opara OC and Dipette DJ: Experimental animal models of hypertension. J Am Soc Hypertens 3: 158-165, 2009.

5. Lerman LO, Chade AR, Sica V and Napoli C: Animal models of hypertension: An overview. J Lab Clin Med 146: 160-173, 2005.

6. Tse G, Tse V and Yeo JM: Ventricular anti-arrhythmic effects of heptanol in hypokalaemic, Langendorff-perfused mouse hearts. Biomed Rep 4: 313-324, 2016.

7. Tse G, Tse V, Yeo JM and Sun B: Atrial anti arrhythmic effects of heptanol in Langendorff perfused mouse hearts. PLoS One 11: e0148858, 2016.

8. Tse G, Wong ST, Tse V and Yeo JM: Restitution analysis of alternans using dynamic pacing and its comparison with S1S2 restitution in heptanol-treated, hypokalaemic Langendorff-perfused mouse hearts. Biomed Rep 4: 673-680, 2016.

9. Tse G, Sun B, Wong ST, Tse V and Yeo JM: Ventricular anti arrhythmic effects of hypercalcaemia treatment in hyperkalaemic, Langendorff perfused mouse hearts. Biomed Rep 5: 301-310, 2016.

10. Tse G, Hothi SS, Grace AA and Huang CL: Ventricular arrhythmogenesis following slowed conduction in heptanol-treated, Langendorff-perfused mouse hearts. J Physiol Sci 62: 79-92, 2012 .

11. Tse G and Yeo JM: Conduction abnormalities and ventricular arrhythmogenesis: The roles of sodium channels and gap junctions. Int J Cardiol Heart Vasc 9: 75-82, 2015. 
12. Tse G, Yeo JM, Tse V, Kwan SK and Sun B: Gap junction inhibition by heptanol increases ventricular arrhythmogenicity by decreasing conduction velocity without affecting repolarization properties or myocardial refractoriness in Langendorff perfused mouse hearts. Mol Med Rep (In press).

13. Leong XF, Ng CY and Jaarin K: Animal models in cardiovascular research: Hypertension and atherosclerosis. BioMed Res Int 2015: 528757, 2015.

14. Doggrell SA and Brown L: Rat models of hypertension, cardiac hypertrophy and failure. Cardiovasc Res 39: 89-105, 1998.

15. Goldblatt H, Lynch J, Hanzal RF and Summerville WW: Studies on experimental: I. the production of persistent elevation of systolic blood pressure by means of renal ischenmia. J Exp Med 9: 347-379, 1934.

16. Gross DR: Animal models of hypertension. In: Animal models in cardiovascular research. Springer Netherlands, Dordrecht, pp475-482, 1994.

17. Terris JM and Simmonds RC: The Yucatan miniature swine: An improved pig model for the study of desoxycorticosterone-acetate (DOCA) and aldosterone hypertension. Proc Soc Exp Biol Med 171: 79-82, 1982

18. Yagil Y and Yagil C: Genetic models of hypertension in experimental animals. Exp Nephrol 9: 1-9, 2001.

19. Twigger S, Lu J, Shimoyama M, Chen D, Pasko D, Long H, Ginster J, Chen CF, Nigam R, Kwitek A, et al: Rat Genome Database (RGD): Mapping disease onto the genome. Nucleic Acids Res 30: 125-128, 2002

20. Trippodo NC and Frohlich ED: Similarities of genetic (spontaneous) hypertension. Man and rat. Circ Res 48: 309-319, 1981.

21. Stoll M and Jacob HJ: Genetic rat models of hypertension: Relationship to human hypertension. Curr Hypertens Rep 3: 157-164, 2001.

22. Fuentes RM, Notkola IL, Shemeikka S, Tuomilehto J and Nissinen A: Familial aggregation of blood pressure: A population-based family study in eastern Finland. J Hum Hypertens 14: 441-445, 2000.

23. Perry IJ, Whincup PH and Shaper AG: Environmental factors in the development of essential hypertension. Br Med Bull 50: 246-259, 1994

24. Williams SM, Haines JL and Moore JH: The use of animal models in the study of complex disease: All else is never equal or why do so many human studies fail to replicate animal findings? BioEssays 26: 170-179, 2004

25. Fuster V, Lie JT, Badimon L, Rosemark JA, Badimon JJ and Bowie EJ: Spontaneous and diet-induced coronary atherosclerosis in normal swine and swine with von Willebrand disease. Arteriosclerosis 5: 67-73, 1985.

26. Fekete A, Rényi Vámos A and Szitás A: Experimental model of renovascular hypertension in dogs. Int Urol Nephrol 2: 391-400, 1970.

27. Hasiwa N, Bailey J, Clausing P,Daneshian M,Eileraas M,Farkas S, Gyertyán I, Hubrecht R, Kobel W, Krummenacher G, et al: Critical evaluation of the use of dogs in biomedical research and testing in Europe. ALTEX 28: 326-340, 2011

28. Wiesel P, Mazzolai L, Nussberger $\mathrm{J}$ and Pedrazzini $\mathrm{T}$ : Two-kidney, one clip and one-kidney, one clip hypertension in mice. Hypertension 29: 1025-1030, 1997.

29. Okamura T, Miyazaki M, Inagami T and Toda N: Vascular renin-angiotensin system in two-kidney, one clip hypertensive rats. Hypertension 8: 560-565, 1986.

30. Yamasaki S: Divided renal and caval vein plasma renin activity in two-kidney two-clip hypertension in rabbits and variations of blood pressure, plasma volume and renal function following unilateral nephrectomy. J Urol 138: 1457-1460, 1987.

31. Sato K, Abe K, Seino M, Yasujima M,Imai Y, Sato M,Hiwatari M, Omata K, Tanno M, Kohzuki M, et al: Renal vein plasma renin activity in patients with unilateral renovascular hypertension. Jpn Circ J 52: 431-436, 1988.

32. Sawamura T and Nakada T: Role of dopamine in the striatum, renin-angiotensin system and renal sympathetic nerve on the development of two-kidney, one-clip Goldblatt hypertension. J Urol 155: 1108-1111, 1996.

33. Zeng J, Zhang Y, Mo J, Su Z and Huang R: Two kidney, two clip renovascular hypertensive rats can be used as stroke prone rats. Stroke 29: 1708-1713, 1998

34. Murphy WR, Coleman TG, Smith TL and Stanek KA: Effects of graded renal artery constriction on blood pressure, renal artery pressure, and plasma renin activity in Goldblatt hypertension. Hypertension 6: 68-74, 1984.

35. Feldman L, Beberashvili I, Averbukh Z and Weissgarten J: Renal artery stenosis of solitary kidney: The dilemma. Ren Fail 26 $525-529,2004$.
36. Brunner HR, Kirshman JD, Sealey JE and Laragh JH Hypertension of renal origin: Evidence for two different mechanisms. Science 174: 1344-1346, 1971.

37. Preston RA and Epstein M: Renal parenchymal disease and hypertension. Semin Nephrol 15: 138-151, 1995.

38. van Koppen A, Verhaar MC, Bongartz LG and Joles JA: 5/6th nephrectomy in combination with high salt diet and nitric oxide synthase inhibition to induce chronic kidney disease in the Lewis rat. J Vis Exp 77: e50398, 2013

39. Moore S and Mersereau WA: Microembolic renal ischemia, hypertension, and nephrosclerosis. Arch Pathol 85: 623-630, 1968.

40. Page IH: A method for producing persistent hypertension by cellophane. Science 89: 273-274, 1939.

41. Selye H, Hall CE and Rowley EM: Malignant hypertension produced by treatment with desoxycorticosterone acetate and sodium chloride. Can Med Assoc J 49: 88-92, 1943.

42. Iyer A, Chan V and Brown L: The DOCA-salt hypertensive rat as a model of cardiovascular oxidative and inflammatory stress. Curr Cardiol Rev 6: 291-297, 2010.

43. Williams SK and Ogedegbe G: Unraveling the mechanism of renin-angiotensin- aldosterone system activation and target organ damage in hypertensive blacks. Hypertension 59: 10-11, 2012.

44. Wilson KM, Sumners C, Hathaway S and Fregly MJ: Mineralocorticoids modulate central angiotensin II receptors in rats. Brain Res 382: 87-96, 1986.

45. Möhring J, Möhring B, Petri M and Haack D: Vasopressor role of $\mathrm{ADH}$ in the pathogenesis of malignant DOC hypertension. Am J Physiol 232: F260-F269, 1977.

46. Li L, Chu Y, Fink GD, Engelhardt JF, Heistad DD and Chen AF Endothelin-1 stimulates arterial VCAM-1 expression via NADPH oxidase-derived superoxide in mineralocorticoid hypertension. Hypertension 42: 997-1003, 2003.

47. Matsumura Y, Hashimoto N, Taira S, Kuro T, Kitano R, Ohkita M, Opgenorth TJ and Takaoka M: Different contributions of endothelin-A and endothelin-B receptors in the pathogenesis of deoxycorticosterone acetate-salt-induced hypertension in rats. Hypertension 33: 759-765, 1999.

48. Zambraski EJ, Ciccone CD and Izzo JL Jr: The role of the sympathetic nervous system in 2-kidney DOCA-hypertensive Yucatan miniature swine. Clin Exp Hypertens A 8: 411-424, 1986.

49. Dahl LK, Knudsen KD, Heine M and Leitl G: Effects of chronic excess salt ingestion. Genetic influence on the development of salt hypertension in parabiotic rats: Evidence for a humoral factor. J Exp Med 126: 687-699, 1967.

50. McCubbin JW, DeMoura RS, Page IH and Olmsted F: Arterial hypertension elicited by subpressor amounts of angiotensin. Science 149: 1394-1395, 1965.

51. Moncada $\mathrm{S}$ and Higgs A: The L-arginine-nitric oxide pathway. N Engl J Med 329: 2002-2012, 1993.

52. Ribeiro MO, Antunes E, de Nucci G, Lovisolo SM and Zatz R: Chronic inhibition of nitric oxide synthesis. A new model of arterial hypertension. Hypertension 20: 298-303, 1992.

53. Lahera V, Salazar J, Salom MG and Romero JC: Deficient production of nitric oxide induces volume-dependent hypertension. J Hypertens Suppl 10 (Suppl 7): S173-S177, 1992.

54. Zatz R and Baylis C: Chronic nitric oxide inhibition model six years on. Hypertension 32: 958-964, 1998.

55. Buñag RD, Takeda K and Riley E: Spontaneous remission of hypertension in awake rats chronically exposed to shaker stress. Hypertension 2: 311-318, 1980.

56. Smookler HH, Goebel KH, Siegel MI and Clarke DE: Hypertensive effects of prolonged auditory, visual, and motion stimulation. Fed Proc 32: 2105-2110, 1973.

57. McCann SM, Rothballer AB, Yeakel EH and Shenkin HA Adrenalectomy and blood pressure of rats subjected to auditory stimulation. Am J Physiol 155: 128-131, 1948.

58. Kaufman LN, Peterson MM and Smith SM: Hypertension and sympathetic hyperactivity induced in rats by high-fat or glucose diets. Am J Physiol 260: E95-E100, 1991.

59. Fregly MJ: Effects of Extremes of temperature on hypertensive rats. Am J Physiol 176: 275-281, 1954.

60. Papanek PE, Wood CE and Fregly MJ: Role of the sympathetic nervous system in cold-induced hypertension in rats. J Appl Physiol (1985) 71: 300-306, 1991.

61. Donaldson GC, Robinson D and Allaway SL: An analysis of arterial disease mortality and BUPA health screening data in men, in relation to outdoor temperature. Clin Sci (Lond) 92: 261-268, 1997. 
62. Brennan PJ, Greenberg G, Miall WE and Thompson SG: Seasonal variation in arterial blood pressure. Br Med J (Clin Res Ed) 285: 919-923, 1982

63. Coste SC, Qi Y, Brooks VL, McCarron DA and Hatton DC: Captopril and stress-induced hypertension in the borderline hypertensive rat. J Hypertens 13: 1391-1398, 1995.

64. Hwang IS, Ho H, Hoffman BB and Reaven GM: Fructose-induced insulin resistance and hypertension in rats. Hypertension 10: 512-516, 1987

65. Garcia EA, Newhouse S, Caulfield MJ and Munroe PB: Genes and hypertension. Curr Pharm Des 9: 1679-1689, 2003.

66. Tabara Y, Kohara K and Miki T; Millennium Genome Project for Hypertension: Hunting for genes for hypertension: The millennium genome project for hypertension. Hypertens Res 35: 567-573, 2012.

67. Mann JF, Phillips MI, Dietz R, Haebara H and Ganten D: Effects of central and peripheral angiotensin blockade in hypertensive rats. Am J Physiol 234: H629-H637, 1978.

68. Yan L, Zhang JD, Wang B, Lv YJ, Jiang H, Liu GL, Qiao Y, Ren $M$ and Guo XF: Quercetin inhibits left ventricular hypertrophy in spontaneously hypertensive rats and inhibits angiotensin II-induced $\mathrm{H} 9 \mathrm{C} 2$ cells hypertrophy by enhancing PPAR- $\gamma$ expression and suppressing AP-1 activity. PLoS One 8: e72548, 2013.

69. Bagby SP, McDonald WJ and Mass RD: Serial renin-angiotensin studies in spontaneously hypertensive and Wistar-Kyoto normotensive rats. Transition from normal- to high-renin status during the established phase of spontaneous hypertension. Hypertension 1: 347-354, 1979.

70. Okamoto K and Aoki K: Development of a strain of spontaneously hypertensive rats. Jpn Circ J 27: 282-293, 1963.

71. Kurtz TW and Morris RC Jr: Biological variability in Wistar-Kyoto rats. Implications for research with the spontaneously hypertensive rat. Hypertension 10: 127-131, 1987.

72. Tobian L, Lange JM, Ulm KM, Wold LJ and Iwai J: Potassium prevents death from strokes in hypertensive rats without lowering blood pressure. J Hypertens Suppl 2: S363-S366, 1984.

73. Mashimo T, Nabika T, Matsumoto C, Tamada T, Ueno K, Sawamura M, Ikeda K, Kato N, Nara Y and Yamori Y: Aging and salt-loading modulate blood pressure QTLs in rats. Am J Hypertens 12: 1098-1104, 1999.

74. Smirk FH and Hall WH: Inherited hypertension in rats. Nature 182: 727-728, 1958.

75. Vincent M, Bornet H, Berthezene F, Dupont J and Sassard J: Thyroid function and blood pressure in two new strains of spontaneously hypertensive and normotensive rats. Clin Sci Mol Med 54: 391-395, 1978.

76. Vincent M, Gomez-Sanchez CE, Bataillard A and Sassard J: Steroids during development of genetic hypertension in rats of Lyon strain. Am J Physiol 257: H506-H510, 1989.

77. Rapp JP and Dene H: Development and characteristics of inbred strains of Dahl salt-sensitive and salt-resistant rats. Hypertension 7: 340-349, 1985.

78. Dahl LK, Heine M and Tassinari L: Effects of chronic excess salt ingestion. Further demonstration that genetic factors influence the development of hypertension: Evidence from experimental hypertension due to cortisone and to adrenal regeneration. J Exp Med 122: 533-545, 1965.

79. Deng Y and Rapp JP: Cosegregation of blood pressure with angiotensin converting enzyme and atrial natriuretic peptide receptor genes using Dahl salt-sensitive rats. Nat Genet 1 : 267-272, 1992

80. Zamir N, Gutman Y and Ben-Ishay D: Hypertension and brain catecholamine distribution in the Hebrew University Sabra, H and N rats. Clin Sci Mol Med Suppl 4: 105s-107s, 1978.

81. Kuijpers MH and Gruys E: Spontaneous hypertension and hypertensive renal disease in the fawn-hooded rat. Br J Exp Pathol 65 181-190, 1984

82. Dobrian AD, Davies MJ, Prewitt RL and Lauterio TJ: Development of hypertension in a rat model of diet-induced obesity. Hypertension 35: 1009-1015, 2000.

83. Mullins LJ, Bailey MA and Mullins JJ: Hypertension, kidney, and transgenics: A fresh perspective. Physiol Rev 86: 709-746, 2006.

84. Lagrange D and Fournié GJ: Generation of congenic and consomic rat strains. Methods Mol Biol 597: 243-266, 2010.

85. Cowley AW Jr, Liang M, Roman RJ, Greene AS and Jacob HJ: Consomic rat model systems for physiological genomics. Acta Physiol Scand 181: 585-592, 2004.

86. Mullins JJ, Peters J and Ganten D: Fulminant hypertension in transgenic rats harbouring the mouse Ren-2 gene. Nature 344 : $541-544,1990$
87. Montgomery HE, Kiernan LA, Whitworth CE, Fleming S, Unger T, Gohlke P, Mullins JJ and McEwan JR: Inhibition of tissue angiotensin converting enzyme activity prevents malignant hypertension in TGR(mREN2)27. J Hypertens 16: 635-643, 1998.

88. Sigmund CD, Jones CA, Kane CM, Wu C, Lang JA and Gross KW: Regulated tissue- and cell-specific expression of the human renin gene in transgenic mice. Circ Res 70: 1070-1079, 1992.

89. Chung O, Schips T, Rohmeiss P, Gretz N, Strauch M and Unger T: Protein excretion and renal adaptation of transgenic mRen 2 rats to changing oral sodium loads. J Hypertens Suppl 11: S188-S189, 1993.

90. Tse G: Novel conduction repolarization indices for the stratification of arrhythmic risk. J Geriatr Cardiol (In press).

91. Tse G: (Tpeak Tend)/QRS and (Tpeak Tend)/(QT x QRS): Novel markers for predicting arrhythmic risk in the Brugada syndrome. Europace (In press).

92. Tse G and Yan BP: Electrophysiological mechanisms of long and short QT syndromes: Insights from mouse models. IJC Heart \& Vasculature (In press)

93. Tse G and Yan BP: Novel arrhythmic risk markers incorporating QRS dispersion: QRSd $\times$ (Tpeak - Tend )/QRS and QRSd $\times($ Tpeak - Tend $) /(\mathrm{QT} \times \mathrm{QRS})$. Ann Noninvasive Electrocardiol Aug 18, 2016 (Epub ahead of print).

94. Tse G,LaiET,Lee AP, Yan BP and Wong SH: Electrophysiological mechanisms of gastrointestinal arrhythmogenesis: Lessons from the heart. Front Physiol 7: 230, 2016.

95. Tse G, Wong ST, Tse V and Yeo JM: Variability in local action potential durations, dispersion of repolarization and wavelength restitution in aged wild type and $\mathrm{Scn} 5 \mathrm{a} /-$ mouse hearts modelling human Brugada syndrome. J Geriatr Cardiol (In press).

96. Tse G: Mechanisms of cardiac arrhythmias. J Arrhythm 32: $75-81,2016$

97. Tse G, Yeo JM, Chan YW, Lai ET and Yan BP: What is the arrhythmic substrate in viral myocarditis? Insights from clinical and animal studies. Front Physiol 7: 308, 2016.

98. Tse G and Yan BP: Traditional and novel electrocardiographic conduction and repolarization markers of sudden cardiac death. Europace (In press).

99. Sun B, Chen Z, Gu J, et al: The roles of tight and gap junctions in the pathogenesis of high fat diet induced atherosclerosis. Int $\mathbf{J}$ Clin Exp Pathol (In press).

100. Sun Z, Cade R, Zhang Z, Alouidor J and Van H: Angiotensinogen gene knockout delays and attenuates cold-induced hypertension. Hypertension 41: 322-327, 2003.

101. Shesely EG, Maeda N, Kim H-S, Desai KM, Krege JH, Laubach VE, Sherman PA, Sessa WC and Smithies O: Elevated blood pressures in mice lacking endothelial nitric oxide synthase. Proc Natl Acad Sci USA 93: 13176-13181, 1996.

102. Sugaya T, Nishimatsu S, Tanimoto K, Takimoto E, Yamagishi T, Imamura K, Goto S, Imaizumi K, Hisada Y, Otsuka A, et al: Angiotensin II type la receptor-deficient mice with hypotension and hyperreninemia. J Biol Chem 270: 18719-18722, 1995.

103. Geller DS, Farhi A, Pinkerton N, Fradley M, Moritz M, Spitzer A, Meinke G, Tsai FT, Sigler PB and Lifton RP: Activating mineralocorticoid receptor mutation in hypertension exacerbated by pregnancy. Science 289: 119-123, 2000.

104. Shimkets RA, Warnock DG, Bositis CM, Nelson-Williams C Hansson JH, Schambelan M, Gill JR Jr, Ulick S, Milora RV, Findling JW, et al: Liddle's syndrome: Heritable human hypertension caused by mutations in the beta subunit of the epithelial sodium channel. Cell 79: 407-414, 1994.

105. Tse G, Wong ST, Tse V, Lee YT, Lin HY and Yeo JM: Cardiac dynamics: Alternans and arrhythmogenesis. J Arrhythm (In press).

106. Tse G, Wong ST, Tse V and Yeo JM: Monophasic action potential recordings: Which is the recording electrode? J Basic Clin Physiol Pharmacol Apr 30, 2016 (Epub ahead of print).

107. Tse G, Lai ET, Yeo JM, Tse V and Wong SH: Mechanisms of electrical activation and conduction in the gastrointestinal system: Lessons from cardiac electrophysiology. Front Physiol 7: $182,2016$.

108. Tse G, Wong ST, Tse V and Yeo JM: Depolarization vs. repolarization: What is the mechanism of ventricular arrhythmogenesis underlying sodium channel haploinsufficiency in mouse hearts? Acta Physiol (Oxf) (In press).

109. Chen Z, Sun B, Tse G, Jiang J and Xu W: Reversibility of both sinus node dysfunction and reduced HCN4 mRNA expression level in an atrial tachycardia pacing model of tachycardia bradycardia syndrome in rabbit hearts. Int J Clin Exp Pathol (In press). 
110. Tse G, Lai ET, Tse V and Yeo JM: Molecular and electrophysiological mechanisms underlying cardiac arrhythmogenesis in diabetes mellitus. J Diabetes Res 2016: 1-8, 2016.

111. Tse G: Both transmural dispersion of repolarization and transmural dispersion of refractoriness are poor predictors of arrhythmogenicity: A role for the index of Cardiac Electrophysiological Balance (QT/QRS)? J Geriatr Cardiol (In press).

112. Tse G, Wong ST, Tse V and Yeo JM: Determination of action potential wavelength restitution in $\mathrm{Scn} 5 \mathrm{a} /$ - mouse hearts modelling human Brugada syndrome. J Physiol (In press).

113. Choy L, Yeo JM, Tse V, Chan SP and Tse G: Cardiac disease and arrhythmogenesis: Mechanistic insights from mouse models. Int J Cardiol Heart Vasc 12: 1-10, 2016.

114. Hu Z, Chen Z, Wang Y, et al: Effects of granulocyte colony stimulating factor on rabbit carotid and swine heart models of chronic obliterative arterial disease. Mol Med Rep (In press).

115. Tse G, Yan BP, Chan YW, Tian XY and Huang Y: Reactive oxygen species, endoplasmic reticulum stress and mitochondrial dysfunction: The link with cardiac arrhythmogenesis. Front Physiol 7: 313, 2016.

116. Tse G, Ali A, Prasad SK, Vassiliou V and Raphael CE: Atypical case of post partum cardiomyopathy: an overlap syndrome with arrhythmogenic right ventricular cardiomyopathy? BJRIcase reports 1: 20150182, 2015 .
117. Tse G, Ali A, Alpendurada F, Prasad S, Raphael CE and Vassiliou V: Tuberculous constrictive pericarditis. Res Cardiovasc Med 4: e29614, 2015.

118. Vassiliou V, Chin C, Perperoglou A, Tse G, Ali A, Raphael C, Jabbour A, Newby D, Pennell D, Dweck M, et al: 93 ejection fraction by cardiovascular magnetic resonance predicts adverse outcomes post aortic valve replacement. Heart 100 (Suppl 3): A53-A54, 2014.

119. Hasenfuss G: Animal models of human cardiovascular disease, heart failure and hypertrophy. Cardiovasc Res 39: 60-76, 1998. Attribution 4.0 International (CC BY 4.0) License. 